\title{
FÍSTULA ABOMASO-UMBILICAL EM BEZERRO: RELATO DE CASO
}

\author{
ALVES, Endrigo Gabellini Leonel ${ }^{1}$ \\ ROSADO, Isabel Rodrigues ${ }^{1}$ \\ MUZZI, Leonardo Augusto Lopes ${ }^{2}$ \\ FELICIANO, Marcus Antônio Rossi ${ }^{3}$ \\ FIDELIS JUNIOR, Otávio Luiz ${ }^{4}$
}

ISSUE DOI: $10.3738 / 1982.2278 .806$

\begin{abstract}
RESUMO: Objetivou-se por meio deste relato a ocorrência de fístula abomaso-umbilical em bezerro Girolando, descrevendo a sintomatologia clínica e tratamento instituído. Um bezerro com quatro meses de idade e $80 \mathrm{~kg}$, apresentou histórico de onfaloflebite e lesão eritematosa com edemaciação umbilical. À inspeção física, verificou-se gotejamento de secreção esbranquiçada com aspecto leitoso e presença de orifício na região umbilical. Verificou-se pela palpação digital a presença de tecido pregueado semelhante mucosa abomasal. Por meio desses achados, sugeriu-se o diagnóstico de fístula abomaso-umbilical e procedeu-se a correção cirúrgica da lesão fistulante. Após 15 dias do tratamento instituído, o animal recebeu alta médica. Dessa forma, pôde-se concluir que, apesar de rara, essa patologia foi de fácil diagnóstico clínico e a terapia foi capaz promover a completa recuperação do animal.
\end{abstract}

Palavras-chave: Bezerro. Fístula abomaso-umbilical. Herniorrafia

\section{ABOMASAL-UMBILICAL FISTULA IN A CALF: CASE REPORT}

SUMMARY: The objective of this report is to show the occurrence of abomasal-umbilical fistula in Girolando calf, describing the clinical symptoms and treatment. A calf with four months of age and $80 \mathrm{~kg}$, presented history of an erythematous lesion with omphalophlebitis and umbilical edema. In the physical inspection, there was dripping of milky white secretion and the presence of an orifice in the umbilical region. It was found by digital palpation the presence of frilled tissue similar to abomasal mucosa. Through these findings, it was suggested the diagnosis of abomasal-umbilical fistula and proceeded the surgical correction of the lesion. After 15 days of the treatment, the animal received a medical discharge. Thus, we conclude that, although rare, this pathology was easily diagnosed and the therapy was able to promote the full recovery of the animal.

Keywords: Calf. Abomasal umbilical fistula. Herniorrafia.

\section{INTRODUÇÃO}

O encarceramento abomasal em anel herniário, com concamitante necrose tecidual e formação de fístula, que é considerado como um processo patológico raro em clinica de ruminantes (BAXTER, 2004; SANGWAN et al., 2011). São poucos os relatos literários acerca desta enfermidade.

De acordo com Baxter (2004) e Sangwan et al. (2011), em bezerros essa afecção deve ser considerada grave devido a perda contínua de ingesta (principalmente leite) juntamente com secreções

\footnotetext{
${ }^{1}$ Doutorando UFMG

${ }^{2}$ Professor Adjunto UFLA

${ }^{3}$ Pós-doutorando UNESP/Jaboticabal - FAPESP

${ }^{4}$ Mestrando UNESP/Jaboticabal
} 
digestivas, promovendo desenvolvimento inadequado dos animais, pela perda de nutrientes, e desequilíbrio eletrolítico e ácido-básico.

Considerando a importância clínica dessa enfermidade, visto o comprometimento observado ao desenvolvimento do animal, essa nota tem como objetivo relatar a ocorrência da fistula abomaso-umbilical em bezerro Girolando, descrevendo a sintomatologia clínica, tratamento instituído e os resultados obtidos.

\section{RELATO DE CASO}

Um bezerro Girolando, fêmea, com quatro meses de idade, pesando $80 \mathrm{~kg}$, foi atendido pelo Serviço de Cirurgia de Grandes Animais do Hospital Veterinário da Universidade Federal de Lavras, com histórico de onfaloflebite.

O animal apresentava lesão eritematosa e edemaciada em região umbilical há quatro meses, sendo que o quadro clínico evoluiu para formação de abscesso e fístula local. Ao exame físico, o animal apresentava-se com parâmetros vitais dentro da normalidade e linfonodos normais à palpação.

À inspeção da lesão umbilical, notou-se constante gotejamento de secreção esbranquiçada com aspecto leitoso, sugerindo a presença de conteúdo gástrico (Figura 1). Essa secreção apresentava aumento no fluxo de drenagem pela fístula, instantes após administração de leite para o animal. Verificou-se ainda a presença de um orifício com aproximadamente dois centímetros de diâmetro.

Figura 1: Imagem de lesão umbilical em bezerro (setas) com a presença de secreção esbranquiçada com aspecto leitoso (A).

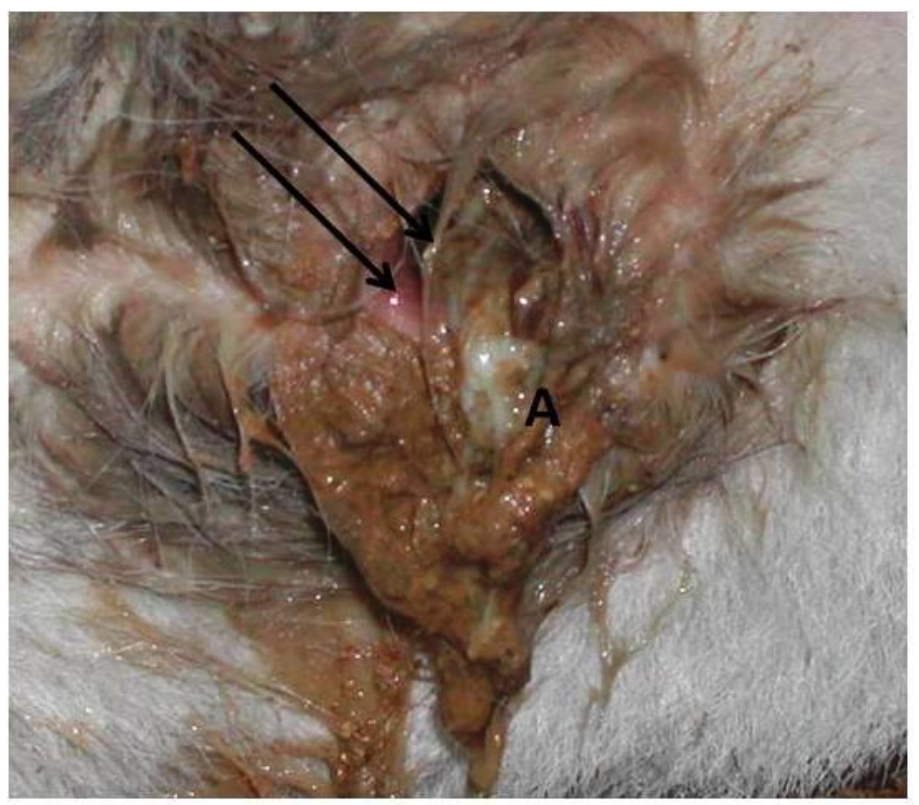

À palpação digital da ferida, percebeu-se que havia tecido fibroso delimitando o trato fistuloso, e mais profundamente, presença de uma cavidade com superfície lisa e amplas pregas longitudinais semelhantes às abomasais. Por meio desses achados foi possível sugerir o diagnóstico de fístula abomasoumbilical, sendo indicada a realização da correção cirúrgica da lesão fistulante, conforme indicado por Kersjes et al. (1985), Rings (1995) e Sangwan et al. (2011). 


\section{DISCUSSÃO}

Como preparo para o procedimento cirúrgico, o animal foi submetido ao jejum alimentar de 12 horas e hídrico de seis horas. Realizou-se sedação com xilazina (Virbaxyl 2\%, Virbac Saúde Animal, Brasil.) $0,1 \mathrm{mg} / \mathrm{kg}$ IM. Após sedação, o animal foi contido e mantido em decúbito lateral direito, sendo realizada ampla tricotomia da região pré e retro umbilical. Em seguida, foi realizada anestesia infiltrativa local com $20 \mathrm{ml}$ de lidocaína 2\% com vasoconstritor (Anestésico L, Pearson Saúde Animal, Brasil), aplicada ao redor da região umbilical (BAXTER, 2004; SILVA et al., 2012). O campo cirúrgico foi preparado de forma asséptica com iodo degermante e álcool iodado e o orifício da fístula foi ocluído com uma boneca de gaze, para evitar o extravasamento de conteúdo abomasal e consequente contaminação do campo cirúrgico.

Após anestesia e preparo do campo iniciou-se o procedimento de hernioplastia, sendo feita incisão cutânea elíptica ao redor do orifício da fistula e em seguida procedeu-se a dissecção romba do trato fistuloso até sua origem abomasal, com o pinçamento das bordas abomasais por meio de duas pinças de Doyen e realizou-se então a ressecção do trato fistuloso (RINGS, 1995).

A abomasorrafia foi realizada em dois planos de sutura: o primeiro de aposição simples contínuo; e o segundo invaginante utilizando o padrão Lembert contínuo, sendo que em ambos planos utilizou-se Categute cromado ${ }^{\circ}$.1. A herniorrafia foi realizada em plano de sutura Sutan e a pele com sutura tipo Wolff, ambas utilizando Nylon 2, conforme técnica preconizada por TRENT (2004).

Para o pós-operatório realizou-se antibioticoterapia profilática com penicilina G Benzatina (Benzetacil, Eurofarma, Brasil) 40.000UI/kg, a cada 72 horas totalizando, em três aplicações. O curativo local foi realizado diariamente com iodo polvidine e a ferida cirúrgica protegida com atadura, durante quinze dias, tempo hábil para retirada dos pontos de sutura da pele. Durante esse o período, o animal permaneceu em baia com espaço restrito. Aos quinze dias de pós-operatório, a ferida cirúrgica apresentava-se cicatrizada e o animal apresentava-se em bom estado de saúde, recebendo alta médica. Após a alta o animal foi acompanhado durante mais três meses e não apresentou nenhum tipo de complicação.

Vertenten et al. (2009) e Sangwan et al. (2011) relataram, de modo semelhante a presente nota, que a presença de fístula abomasal é raramente descrita em associação com hérnia umbilical e a onfaloflebite. De acordo Parker; e Fubini (1987), essa enfermidade é mais comumente observada em vacas adultas submetidas à abomasopexia para tratamento de descolcamento de abomaso.

O principal sinal observado em animais jovens com fístula abomasal em hérnia abomasoumbilical é a presença de secreção com aspecto de ingesta, que no presente relato era um conteúdo esbranquiçado semelhante ao leite ingerido pelo animal. Esse achado também foi observado por Newcomb; Morton (1970), Fubini; Smith (1984); Sangwan et al. (2011).

O tratamento adotado no presente relato foi semelhante ao citado por Newcomb; Morton (1970), Fubini; Smith (1984), Vertenten et al. (2009) e Sangwan et al., (2011).

\section{CONCLUSÃO}

Pôde-se concluir que os achados clínicos são suficientes para o diagnóstico dessa emfermidade, e que o tratamento cirúrgico é recomendável e apresenta sucesso terapêutico, sem complicações para os animais acometidos. 


\section{REFERÊNCIAS}

BAXTER, G.M. Hernias/Umbilicus. In: FUBINI, S.; DUCHARME, N. Farm Animal Surgery. St. Louis, Missouri: Saunders, cap. 14, p.477-484. 2004.

ČÍTEK, J. et al. Congenital disorders in the cattle population of the Czech Republic. Czech Journal of Animal Science, v.54, p.55-64, 2009.

FUBINI, S.L.; SMITH, D.F. Umbilical hernia with abomasal-umbilical fistula in a calf. Journal of the American Veterinary Medical Association, v.184, n.12, p.1510-1511, 1984.

KERSJES, A.W. et al. The Abdomen. In: Williams \& Wilkins, cap. 4, p. 30-50, 1985. . Atlas of Large Animal Surgery. Baltimore, London:

NEWCOMB, R.; MORTON, T.C. A case of abomasal-umbilical fistula in a calf. Veterinary Record, v.87, p.803, 1970.

PARKER, J.E.; FUBINI, S.L. Abomasal fistulas in dairy cows. The Cornell Veterinarian, v.77, n.4, p.303-309, 1987.

RINGS D.M. Umbilical hernias, umbilical abscesses, and urachal fistulas. Veterinary Clinics of North America: Food Animal Practice, v.11, p.137-148, 1995.

SANGWAN, V. et al. Umbilical hernia with abomasal-umbilical fistula in a cow calf. Vet Scan Online Veterinary Journal, v.6, n.1, p.83, 2011.

SILVA, L.A.F. et al. Tratamento de hérnia umbilical em bovinos. Revista Ceres, v.59, n.1, p. 39-47, 2012.

TRENT, A.M. Surgery of the Abomasum. In: FUBINI, S.; DUCHARME, N. Farm Animal Surgery. St. Louis, Missouri: Saunders, cap. 10, p.196-240, 2004.

VERTENTEN, G. et al. Abomasal end-to-end anastomosis as treatment for abomasal fistulation and hernation in a cow. Veterinary Record, v.164, p.785-786, 2009. 